\title{
Effect of flaxseed on choroid-sclera complex thickness and on LDL oxidation in the sclera, choroid and retina of diet-induced hypercholesterolaemic rabbits
}

Rogil José de Almeida Torres ${ }^{1 *}$, Andrea Luchini ${ }^{2}$, Alessandro Soares Both ${ }^{3}$, Leonardo Brandao Precoma ${ }^{4}$, Ana Flavia Champoski ${ }^{3}$, Maynara Leonardi Schuh ${ }^{5}$, Renan Pedro de Almeida Torres ${ }^{6}$, Lucia Noronha ${ }^{7}$, Bernardo Molinari Pessoa ${ }^{5}$, Lucas Antonio de Almeida Torres ${ }^{8}$, Nicole Francesca de França Serci ${ }^{5}$ and Dalton Bertolim Precoma ${ }^{9}$

${ }^{1}$ Department of Opthalmology, Pontificia Universidade Catolica do Parana, Rua Emiliano Perneta 390, Conj 1407, CEP 80420-080, Curitiba, Parana, Brazil

${ }^{2}$ Centro Oftalmologico de Curitiba, Curitiba, Parana, Brazil

${ }^{3}$ Health Sciences, Pontificia Universidade Catolica do Parana, Curitiba, Parana, Brazil

${ }^{4}$ Medical Clinic, Hospital Angelina Caron, Campina Grande do Sul, Parana, Brazil

${ }^{5}$ Pontificia Universidade Catolica do Parana, Curitiba, Parana, Brazil

${ }^{6}$ Universidade Federal do Parana, Curitiba, Parana, Brazil

${ }^{7}$ Department of Pathology, Pontificia Universidade Catolica do Parana, Curitiba, Parana, Brazil

${ }^{8}$ Hospital de Olhos do Parana, Curitiba, Parana, Brazil

${ }^{9}$ Post-Graduation Programs in Health Sciences and in Surgery, Department of Cardiology, Pontificia Universidade Catolica do Parana, Curitiba, Parana, Brazil

(Submitted 3 April 2014 - Final revision received 14 June 2014 - Accepted 17 July 2014 - First published online 23 September 2014)

\section{Abstract}

The aim of the present study was to evaluate the effect of flaxseed on choroid-sclera complex thickness and on LDL oxidation in the sclera, choroid and retina of diet-induced hypercholesterolaemic rabbits. New Zealand male albino rabbits $(n$ 21) were divided into two groups: group 1 (G1;n 11), fed a hypercholesterolaemic diet, and group 2 (G2;n 10), fed a hypercholesterolaemic diet enriched with flaxseed flour. The serum concentrations of total cholesterol (TC), LDL-cholesterol (LDL-C), HDL-cholesterol, TAG and fasting blood glucose were determined at the start of the experiment and on the day of killing (8th week). Choroid and sclera samples were subjected to haematoxylin-eosin (HE) staining and histomorphometric and immunohistochemical analyses with the anti-oxidised LDL antibody. Sensory retina samples were subjected to an immunohistochemical analysis with the primary monoclonal nitrotyrosine antibody. At the end of the experiment, a significant increase was observed in TC and LDL-C concentrations in G1 rabbits when compared with G2 rabbits $(P=0.008$ and $P=0 \cdot 02$, respectively). HE staining revealed a significant increase in choroid-sclera complex thickness in G1 rabbits when compared with G2 rabbits $(P<0 \cdot 001)$. Immunohistochemical analysis of choroid and sclera samples with the anti-oxidised LDL marker revealed a significant increase in immunoreactivity in G1 rabbits when compared with G2 rabbits $(P<0 \cdot 001)$. Immunohistochemical analysis of sensory retina samples with the anti-nitrotyrosine marker revealed a significant increase in immunoreactivity in G1 rabbits when compared with G2 rabbits $(P=0 \cdot 002)$. Flaxseed reduced the choroid-sclera complex thickness of diet-induced hypercholesterolaemic rabbits and the expression of oxidised LDL in the choroid-sclera complex as well as the expression of nitrotyrosine in the sensory retina.

Key words: Flaxseed: Macular degeneration: LDL: Macrophages: Sclera, choroid and retina

Abbreviations: AMD, age-related macular degeneration; G1, group 1; G2, group 2; LDL-C, LDL-cholesterol; NOS, NO synthase; RPE, retinal pigment epithelium; TC, total cholesterol.

* Corresponding author: R. J. d. A. Torres, email rjat@terra.com.br 
Age-related macular degeneration (AMD) is one of the main causes of irreversible blindness in older people ${ }^{(1)}$. It is a complex disease triggered by factors that are fundamentally associated with old age and genetic and environmental alterations $^{(2)}$. Histopathological studies have shown that retinal pigment epithelium (RPE), Bruch's membrane and choriocapillaris are primarily involved in this pathological process $^{(3)}$. It has been suggested that a gradual anomalous deposition of lipids in Bruch's membrane ${ }^{(3)}$, originating from the dysfunction of RPE cells ${ }^{(4)}$, leads to an increase in its thickness ${ }^{(5)}$, directly interfering with the metabolism of sensory retina, RPE and choriocapillaris ${ }^{(3,5-8)}$. It is known that oxidised LDL represent an important stimulus for the increase in the concentrations of chemotactic and adhesion molecules that attract macrophages. These cells produce inflammatory cytokines, tissue factors, vascular endothelial growth factor and other angiogenic factors ${ }^{(9-13)}$, triggering or worsening the macular degenerative process ${ }^{(14)}$.

It has already been documented experimentally that a cholesterol-enriched diet induces an increase in the concentrations of chemotactic molecules and adhesion molecules and a consequent increase in the accumulation of macrophages in the choroid and sclera ${ }^{(15-17)}$. It has also been demonstrated that this diet induces a retinal suffering $^{(18)}$ and a consequent increase in the expression of NO synthase (NOS) $2^{(19)}$. Both the increase in macrophage accumulation and ischaemia may be responsible for the increase in vascular endothelial growth factor expression observed in the choroid-sclera complex of hypercholesterolaemic rabbits ${ }^{(20)}$. Consequently, a hypercholesterolaemic diet can experimentally simulate the alterations observed in AMD.

Flaxseed is a functional food rich in $\alpha$-linolenic acid that exhibits anti-inflammatory, antithrombotic and antihypertensive effects ${ }^{(21,22)}$. Epidemiological studies have shown that there is an association between the consumption of $n-3$ fatty acids and the prevention of AMD, as it slows the progression of the disease at its early stages ${ }^{(23-25)}$. Lignans, another component of flaxseed, inhibit the proliferation of vascular endothelial cells and reduce the oxidation of $\mathrm{LDL}^{(26,27)}$. Due to the significant involvement of oxidative stress in the pathogenesis of $\mathrm{AMD}^{(28)}$, flaxseed can potentially inhibit the progression of macular degenerative disease. In addition, its fibres decrease cholesterol concentrations in the blood and liver ${ }^{(29,30)}$, playing a beneficial role in the evolution of $\mathrm{AMD}^{(31-33)}$.

The aim of the present study was to evaluate the effect of flaxseed on choroid-sclera complex thickness and on LDL oxidation in the sclera, choroid and retina of diet-induced hypercholesterolaemic rabbits.

\section{Methods}

The study protocol was approved by the Animal Experimentation Ethics Committee of the Pontificia Universidade Catolica do Parana and was implemented in compliance with the guidelines established by the Association for Research in Vision and Ophthalmology.

\section{Experiment environment}

The experimental procedures were performed at the Surgical Technique Laboratory at PUC-PR and the Study Center of the Hospital Angelina Caron. The animals were kept in the bioterium (macroenvironment) under a $12 \mathrm{~h}$ light-12 h dark cycle, with air changes and room temperature maintained between 19 and $23^{\circ} \mathrm{C}$. The animals were given water and standard Nuvilab $^{\circledR}$ (Nuvital) rabbit chow (Table 1) ad libitum 2 weeks before the start of the experiment.

\section{Animals used and experiment outline}

A total of twenty-one 4-month-old New Zealand male albino rabbits (Oryctolagus cuniculus), weighing about $1.5 \mathrm{~kg}$, were used in the study. The animals were divided into two groups: group 1 (G1; eleven animals), fed the standard rabbit diet Nuvilab ${ }^{\circledR}$ (Nuvital) enriched with $0.5 \%$ cholesterol freeze-dried egg for 8 weeks, and group 2 (G2; ten animals), fed the same diet provided to $\mathrm{G} 1$ rabbits plus $8 \mathrm{~g} / \mathrm{kg}$ ground brown flaxseed of Brazilian origin. Each G2 rabbit was fed an average amount of $30 \mathrm{~g}$ of flaxseed for 8 weeks. The $0.5 \%$ cholesterol-enriched diet, used throughout the experiment, was obtained by diluting $600 \mathrm{~g}$ of powdered egg in $500 \mathrm{ml}$ of water.

The serum concentrations of total cholesterol (TC), LDL-cholesterol (LDL-C), TAG and fasting glucose of each rabbit were

Table 1. Composition of Nuvilab ${ }^{\circledR}$ (Nuvital) rabbit feed ${ }^{\star}$

\begin{tabular}{|c|c|}
\hline \multicolumn{2}{|l|}{$1 \mathrm{~kg}$ of the product contains: } \\
\hline Moisture content (max) (\%) & $12 \cdot 5$ \\
\hline Crude protein $(\mathrm{min})(\%)$ & $16 \cdot 00$ \\
\hline Ethereal extract $(\mathrm{min})(\%)$ & 3.00 \\
\hline Mineral matter (max) $(\%)$ & $10 \cdot 00$ \\
\hline Fibre $(\max )(\%)$ & 14.00 \\
\hline $\mathrm{Ca}(\max )(\%)$ & 1.00 \\
\hline $\mathrm{P}(\min )(\%)$ & 0.60 \\
\hline $\mathrm{Fe}(\mathrm{mg})$ & $40 \cdot 00$ \\
\hline $\mathrm{Zn}(\mathrm{mg})$ & $60 \cdot 00$ \\
\hline $\mathrm{Cu}(\mathrm{mg})$ & 6.00 \\
\hline $\mathrm{I}(\mathrm{mg})$ & 0.30 \\
\hline $\mathrm{Mg}(\mathrm{mg})$ & $40 \cdot 00$ \\
\hline $\mathrm{Se}(\mathrm{mg})$ & 0.10 \\
\hline Co (mg) & 1.00 \\
\hline DL-Met (mg) & $100 \cdot 00$ \\
\hline Antioxidant (mg) & $100 \cdot 00$ \\
\hline Vitamin A (IU) & 6000 \\
\hline Vitamin $D_{3}(I U)$ & 900 \\
\hline Vitamin E (mg) & $15 \cdot 00$ \\
\hline Vitamin $\mathrm{K}_{3}(\mathrm{mg})$ & 1.00 \\
\hline Vitamin $B_{1}(\mathrm{mg})$ & $2 \cdot 00$ \\
\hline Vitamin $B_{2}(\mathrm{mg})$ & $6 \cdot 00$ \\
\hline Vitamin $\mathrm{B}_{6}(\mathrm{mg})$ & $2 \cdot 00$ \\
\hline Vitamin $B_{12}(\mu \mathrm{g})$ & $10 \cdot 00$ \\
\hline Niacin $(\mathrm{mg})$ & 30.00 \\
\hline Pantothenic acid (mg) & $17 \cdot 00$ \\
\hline Folic acid (mg) & 1.00 \\
\hline Biotin (mg) & 0.03 \\
\hline Choline (mg) & $300 \cdot 00$ \\
\hline
\end{tabular}


measured at the start of the experiment and at the time of killing. These concentrations were determined with an automated enzymatic method, using the Bayer ADVIA $1200{ }^{\circledR}$ Clinical Chemistry System (Siemens). Blood samples were collected by marginal ear vein puncture under general anaesthesia with $15 \mathrm{mg} / \mathrm{kg}$ of ketamine and $35 \mathrm{mg} / \mathrm{kg}$ of xylazine. The animals were killed under endovenous anaesthesia with $5 \mathrm{ml}$ of pentobarbital, and their eyes were immediately placed in $4 \%$ paraformaldehyde (Merck) in $0 \cdot 1 \mathrm{M}$-phosphate ( $\mathrm{pH} 7 \cdot 4)$ for $4 \mathrm{~h}$ for immunohistochemical analysis.

\section{Histomorphometric analysis (quantitative)}

The eyes of each rabbit were removed and fixed for analysis. However, only one eye was randomly selected. After fixation, the samples were evaluated macroscopically using a coronal section at the optic nerve level, dividing the eye globes into two equal halves (lower and upper). The lower half was stored for future studies. The upper half was dehydrated, diaphanised and embedded in paraffin using a Leica ${ }^{\circledR}$ histotechnique system (Leica), model TP 1020. The Leica ${ }^{\circledR}$ EG 1160 Embedding Station (Leica) was used to prepare the paraffin blocks. These blocks were sectioned at $5 \mu \mathrm{m}$ using a Leica ${ }^{\circledR}$ RM2145 microtome (Leica) to obtain histological sections, which were then placed on albumin-smeared glass slides, stained with haematoxylineosin and mounted on $24 \times 90 \mathrm{~mm}$ cover slips, with Entellan Mounting Media (Merck).
The haematoxylin-eosin-stained slides were evaluated with the aid of a $4 \times$ objective lens and a blue overhead projector marker for quantitative analysis. The posterior portion of the hemi-sectioned ocular globe was manually divided into ten equal segments (from the pars plana to the contralateral pars plana). Images of the segments were obtained using an Olympus BX50 microscope (Olympus) coupled to a Sony camera (Sony Corporation). The choroid-sclera complex thickness of the ten segments was determined by performing four linear morphometric measurements in each captured image using the Image Pro Plus ${ }^{\circledR}$ software (Media Cybernetics, Inc.). Later, the mean of the four measurements of each of the ten segments was obtained. The thickness is expressed in $\mu \mathrm{m}$.

\section{Tissue preparation and immunohistochemical analysis}

The histological slides were deparaffinised and rehydrated and then treated to block the endogenous peroxidase. The slides were washed with deionised water and incubated in a wet chamber at $95^{\circ} \mathrm{C}$ for $20 \mathrm{~min}$ for antigen recovery. After this step, the endogenous peroxidase was blocked again. The slides were stained with $\mathrm{Abcam}^{\circledR}$ anti-oxidised LDL antibody of mouse origin, at a 1:600 dilution, for the analysis of choroid and sclera samples. The mouse Santa Cruz ${ }^{\circledR}$ (Santa Cruz Biotechnology) primary monoclonal nitrotyrosine, at a 1:50 dilution, was used for the analysis of sensory retina samples. The slides were then stained with a secondary

Table 2. Values of the biochemical variables and weight at the start and end of the experiment

(Mean values and standard deviations; median, minimum and maximum values)

\begin{tabular}{|c|c|c|c|c|c|c|c|c|}
\hline Variables & Group & $n$ & Mean & Median & Minimum & Maximum & SD & $P^{\star}$ \\
\hline \multirow[t]{2}{*}{ Total cholesterol - start } & G1 & 11 & $75 \cdot 8$ & 63.0 & $33 \cdot 0$ & $138 \cdot 0$ & $36 \cdot 7$ & \\
\hline & G2 & 10 & $58 \cdot 8$ & 65.5 & $31 \cdot 0$ & $69 \cdot 0$ & 11.9 & 0.171 \\
\hline \multirow[t]{2}{*}{ Total cholesterol - end } & G1 & 11 & $642 \cdot 3$ & 666.0 & $36 \cdot 0$ & $1057 \cdot 0$ & 392.4 & \\
\hline & G2 & 10 & 289.0 & 258.5 & $106 \cdot 0$ & 686.0 & $196 \cdot 0$ & 0.018 \\
\hline \multirow[t]{2}{*}{ Dif in total cholesterol } & G1 & 11 & 566.5 & 603.0 & 3.0 & 972.0 & $372 \cdot 7$ & \\
\hline & G2 & 10 & 230.2 & 199.0 & $51 \cdot 0$ & 619.0 & 193.6 & 0.019 \\
\hline \multirow[t]{2}{*}{ LDL-cholesterol - start } & G1 & 11 & 34.8 & 14.7 & 1.3 & 97.0 & 33.7 & \\
\hline & G2 & 10 & 11.9 & $12 \cdot 7$ & 0.6 & 22.7 & $6 \cdot 2$ & 0.049 \\
\hline \multirow[t]{2}{*}{ LDL-cholesterol - end } & G1 & 11 & 605.4 & 613.8 & 8.3 & 1017.4 & $390 \cdot 1$ & \\
\hline & G2 & 10 & $262 \cdot 3$ & 233.9 & 79.8 & 649.4 & 193.3 & 0.024 \\
\hline \multirow[t]{2}{*}{ Dif in LDL-cholesterol } & G1 & 11 & 570.6 & 586.8 & 7.0 & 971.4 & 370.2 & \\
\hline & G2 & 10 & 250.3 & 220.0 & 75.5 & $626 \cdot 7$ & $189 \cdot 7$ & 0.024 \\
\hline \multirow[t]{2}{*}{ HDL-cholesterol - start } & G1 & 11 & 21.3 & 25.0 & 5.0 & 33.0 & $9 \cdot 3$ & \\
\hline & G2 & 10 & $23 \cdot 8$ & 23.5 & $13 \cdot 0$ & 33.0 & $5 \cdot 8$ & 0.469 \\
\hline \multirow[t]{2}{*}{ HDL-cholesterol - end } & G1 & 11 & 23.7 & 22.0 & $15 \cdot 0$ & 46.0 & 8.8 & \\
\hline & G2 & 10 & $15 \cdot 1$ & 14.5 & 8.0 & $21 \cdot 0$ & $4 \cdot 0$ & 0.011 \\
\hline \multirow[t]{2}{*}{ Dif in HDL-cholesterol } & G1 & 11 & 2.5 & 3.0 & $-15 \cdot 0$ & $21 \cdot 0$ & 11.7 & \\
\hline & G2 & 10 & -8.7 & -9.5 & $-17 \cdot 0$ & 2.0 & 6.5 & 0.016 \\
\hline \multirow[t]{2}{*}{ TAG - start } & G1 & 11 & 98.5 & 89.0 & $54 \cdot 0$ & 198.0 & $40 \cdot 6$ & \\
\hline & G2 & 10 & $157 \cdot 6$ & $116 \cdot 0$ & $72 \cdot 0$ & $326 \cdot 0$ & $92 \cdot 1$ & 0.086 \\
\hline \multirow{2}{*}{ TAG - end } & G1 & 11 & 65.6 & 58.0 & $31 \cdot 0$ & 113.0 & $26 \cdot 2$ & \\
\hline & G2 & 10 & 58.2 & 56.0 & 29.0 & 105.0 & $27 \cdot 3$ & 0.532 \\
\hline \multirow[t]{2}{*}{ Dif in TAG } & G1 & 11 & -32.8 & -23.0 & $-156 \cdot 0$ & 38.0 & $48 \cdot 8$ & \\
\hline & $\mathrm{G} 2$ & 10 & -99.4 & $-66 \cdot 0$ & -297.0 & $17 \cdot 0$ & $103 \cdot 3$ & 0.087 \\
\hline \multirow{2}{*}{ Weight - start } & G1 & 11 & 1881.8 & 1840.0 & 1580.0 & 2550.0 & $266 \cdot 6$ & \\
\hline & G2 & 10 & 2087.5 & 2142.5 & $1480 \cdot 0$ & 2680.0 & $342 \cdot 2$ & 0.139 \\
\hline \multirow[t]{2}{*}{ Weight - end } & G1 & 11 & 2975.5 & 3050.0 & 2720.0 & 3165.0 & 164.9 & \\
\hline & G2 & 10 & 3078.5 & 3002.5 & $2400 \cdot 0$ & $3700 \cdot 0$ & $400 \cdot 1$ & 0.463 \\
\hline \multirow[t]{2}{*}{ Dif in weight } & G1 & 11 & 1093.6 & $1120 \cdot 0$ & $550 \cdot 0$ & 1585.0 & 276.9 & \\
\hline & G2 & 10 & 991.0 & 985.0 & 660.0 & 1430.0 & $222 \cdot 3$ & 0.364 \\
\hline
\end{tabular}

G1, cholesterol-enriched diet group; G2, cholesterol-enriched diet plus flaxseed supplementation group; Dif, difference.

* Student's $t$ test for independent samples $(P<0.05)$. 
Table 3. $P$ values* for the differences in the biochemical variables and weight at the start and end of the experiment

\begin{tabular}{lrr}
\hline & \multicolumn{2}{c}{$P($ start $v$. end $)$} \\
\cline { 2 - 3 } Variables & \multicolumn{1}{c}{ G1 } & \multicolumn{1}{c}{ G2 } \\
\hline Total cholesterol & 0.001 & 0.004 \\
LDL-cholesterol & $<0.001$ & 0.002 \\
HDL-cholesterol & 0.504 & 0.002 \\
TAG & 0.050 & 0.014 \\
Weight & $<0.001$ & $<0.001$ \\
\hline
\end{tabular}

G1, cholesterol-enriched diet group; G2, cholesterol-enriched diet plus flaxseed supplementation group.

* Student's $t$ test for paired samples $(P<0.05)$

antibody, Polymer HRP anti-mouse/rat Detection System (DakoCytomation, Inc.), and incubated at room temperature for $30 \mathrm{~min}$. They were then stained by dripping a freshly prepared diaminobenzidine-mixed substrate (DakoCytomation, Inc.) and once again incubated for 3-5 min. The slides were counterstained with Mayer haematoxylin and mounted.

Positive and negative controls were used in all evaluations, and the slides were initially analysed by a masked observer. In this analysis, positive and negative results were recorded for the oxidised LDL and nitrotyrosine markers. The positive areas acquired a brownish hue and were studied by colour morphometry. This procedure was performed by capturing images of five consecutive fields, from the pars plana to the contralateral pars plana, with a $40 \times$ objective lens coupled to a Olympus BX50 microscope (Olympus), which was coupled to a Sony DXC-107A camera (Sony Corporation) and the Image Pro Plus ${ }^{\circledR}$ software (Media Cybernetics, Inc.). This software enabled the observer to select and colour the positive areas and automatically calculate the immunoreactive area, expressed in $\mu \mathrm{m}^{2}$. The data obtained were compiled into a Microsoft Excel spreadsheet (Microsoft Corporation) for statistical analysis. The variable immunoreactive area represents the sum of all positive areas in each of the five studied fields. This colour morphometry method has already been used in other studies ${ }^{(15-18,20)}$

\section{Statistical analysis}

Student's $t$ test for independent samples was used to compare the treatment groups in relation to quantitative variables. The evaluations performed at the start of the experiment and at the time of killing were compared using Student's $t$ test for paired samples. The normality condition was evaluated using the Shapiro-Wilk test. The variables that did not present a symmetric condition were submitted to a logarithmic transformation. $P$ values $<0.05$ indicated statistical significance. STATISTICA version 8.0 (StatSoft) was used for data processing.

\section{Results}

\section{Biochemical variables}

The average daily hypercholesterolaemic diet intake was approximately $200 \mathrm{~g}$ in both groups. At the start of the experiment, there was no significant difference in the biochemical variables and weight between G1 and G2 rabbits. At the time of killing, a significant increase was observed in TC concentrations in both groups, which was greater in G1 rabbits than in G2 rabbits. Nevertheless, the increase in G2 rabbits was approximately five times the initial level, whereas that in G1 rabbits was eight times the initial level. Similar results were recorded for LDL-C concentrations, with G1 rabbits exhibiting a significant increase when compared with G2 rabbits at the end of the experiment.

No significant changes were observed in the remaining variables. Values of the biochemical variables and weight at the start and end of the experiment (at the time of killing) are given in Table 2. $P$ values for the differences in the biochemical variables and weight at the start and end of the experiment are given in Table 3 .

\section{Histomorphometric analysis with haematoxylin-eosin}

There was an increase in the concentrations of macrophages in G1 rabbits when compared with G2 rabbits (Fig. 1), which induced a significant increase in choroid-sclera complex thickness in G1 rabbits when compared with G2 rabbits $(P<0 \cdot 001$; Table 4$)$.

\section{Immunohistochemical analysis of the choroid and sclera with the anti-oxidised LDL marker}

A significant increase was observed in the expression of the anti-oxidised LDL marker in the choroid and sclera of G1 rabbits when compared with $\mathrm{G} 2$ rabbits $(P<0 \cdot 001$; Table 5). A brownish hue was predominant in the choroid-sclera complex of G1 rabbits, revealing a high immunoreactivity to this marker (Fig. 2). Conversely, a bluish hue was predominant in the choroid-sclera complex of G2 rabbits, revealing a low immunoreactivity to this marker.

\section{Immunohistochemical analysis of the retina with the anti-nitrotyrosine marker}

A significant increase was observed in the expression of the anti-nitrotyrosine marker in G1 rabbits when compared with

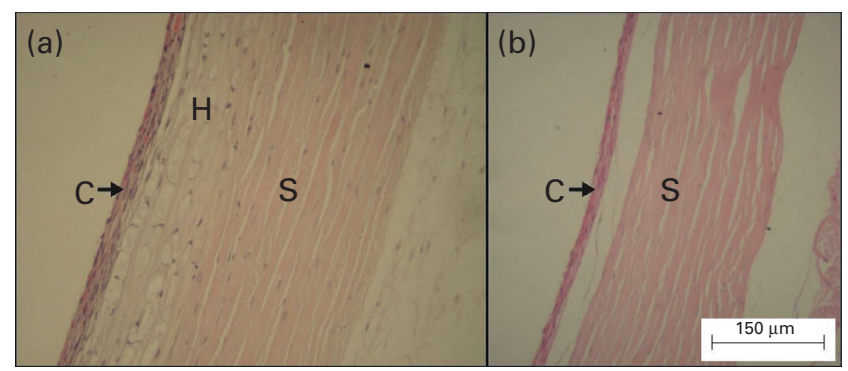

Fig. 1. Histomorphometric analysis of choroid (C) and sclera (S) samples with haematoxylin-eosin. Magnification 200x. (a) C-S complex of the cholesterol-enriched diet group (G1). A large number of histiocytes $(H)$, responsible for $\mathrm{C}-\mathrm{S}$ complex thickness, were observed. (b) $\mathrm{C}-\mathrm{S}$ complex of the cholesterol-enriched diet plus flaxseed supplementation group. Few $\mathrm{H}$ and a thinner layer were observed when compared with the samples of G1 rabbits. 
Table 4. Choroid and sclera morphometry (in $\mu \mathrm{m}$ )

(Mean values and standard deviations; median, minimum and maximum values)

\begin{tabular}{lcccccccc}
\hline Variable & Group & $n$ & Mean & Median & Minimum & Maximum & SD & $P^{\star}$ \\
\hline Choroid and sclera morphometry & G1 & 11 & 713.0 & 712.5 & 634.2 & 803.1 & 62.5 & \\
& G2 & 10 & 498.0 & 484.2 & 416.2 & 634.0 & 63.8 & $<0.001$ \\
\hline
\end{tabular}

G1, cholesterol-enriched diet group; G2, cholesterol-enriched diet plus flaxseed supplementation group.

*Student's $t$ test for independent samples $(P<0.05)$.

G2 rabbits $(P=0.002$; Table 6). A brownish hue was predominant in the sensory retina of $\mathrm{G} 1$ rabbits, revealing a high immunoreactivity to this marker (Fig. 3). The internal plexiform layer exhibited a higher immunoreactivity to this marker when compared with the other layers. Conversely, a bluish hue was predominant in the retina of G2 rabbits, revealing a low immunoreactivity to this marker.

\section{Discussion}

In the present study, diet-induced hypercholesterolaemic rabbits were supplemented with flaxseed to investigate its effect on choroid-sclera complex thickness and on LDL oxidation in the sclera, choroid and retina. It is known that in the great vessels, such as the coronary and carotid arteries, dyslipidaemia induces endothelial dysfunction, permitting the passive entry of LDL into the vascular intima, where the LDL become oxidised by the action of reactive oxygen species. Oxidised LDL stimulate the endothelial cells of the vessels to increase the expression of vascular adhesion molecules (P-selectin, intercellular adhesion molecule and vascular cell adhesion molecule 1), which, along with monocyte chemoattractant protein-1 ligands and their C-C chemokine receptor type 2 receptors, facilitate the activation of monocytes and their adhesion to the endothelium. The monocytes, by means of the scavenger receptors (CD36 and SR-A), absorb the oxidised LDL and form histiocytes. These histiocytes, in turn, express inflammatory cytokines, enzymes and growth factors, which, along with the cytokines released by the activated $\mathrm{T}$ cells, promote the inflammatory process and the proliferation and migration of the smooth muscle and endothelial cells into the vessel intima, thus forming the atherosclerotic plaque $^{(34-36)}$

One of the beneficial effects of flaxseed is its role in the reduction of serum TC and LDL-C concentrations. Adequate cholesterol concentrations are important for the prevention of CVD. Studies have reported decreases in plasma TC and LDL-C concentrations ranging from 5 to $15 \%$, depending on the amount of $n-3$ consumed ${ }^{(37,38)}$. A study carried out using $50 \mathrm{~g} / \mathrm{d}$ flaxseed supplementation for 4 weeks has reported reductions of 9 and 18\% in serum TC and LDL-C concentrations, respectively ${ }^{(39)}$. Similarly, another study carried out using 20 and $30 \%$ flaxseed supplementation has reported reductions of 21 and $33 \%$ in plasma TC concentrations and of 33 and $67 \%$ in plasma LDL-C concentrations, respectively ${ }^{(40)}$. The inclusion of $15 \%$ flaxseed in the diet of hypercholesterolaemic rabbits has been found to prevent the progression of hypercholesterolaemia and to significantly reduce serum TC (13\%) and LDL-C (44\%) concentrations ${ }^{(41)}$. Another study has reported a reduction of $33 \%$ in TC concentrations and of $35 \%$ in LDL-C concentrations ${ }^{(42)}$. In the present study, both groups exhibited a similar increase in serum TC and LDL-C concentrations. Nevertheless, G1 rabbits exhibited a final cholesterol concentration that was eight times the initial level. On the other hand, G2 rabbits exhibited final plasma TC and LDL-C concentrations that were significantly lower than those of G1 rabbits. These results show the beneficial effects of flaxseed on TC and LDL-C concentrations in G2 rabbits, which did not exhibit an increase in concentrations as G1 rabbits did. Similar findings were recorded in an 8-week study that analysed the effect of lignan in rabbits ${ }^{(43,44)}$.

It has been experimentally demonstrated that a cholesterolenriched diet induces an increase in the concentrations of macrophages in the choroid and $\operatorname{sclera}^{(17,45)}$. These cells, considered essential for the origin of atherosclerotic plaques ${ }^{(34)}$, have also been reported to be associated with $\operatorname{AMD}^{(9,46,47)}$. In addition, it has been suggested that AMD and atherosclerosis share similar physiopathogenic mechanisms ${ }^{(33)}$. The present study corroborates the findings of earlier studies that hypercholesterolaemia may induce the same events in the choroid-sclera complex. The exacerbated expression of oxidised LDL in the choroid and sclera observed in G1 rabbits could account for the increase in the expression of chemotactic molecules ${ }^{(15)}$, such as monocyte chemoattractant protein-1, adhesion molecules $^{(16)}$ and intercellular adhesion molecule-1, which would induce an increase in macrophage concentrations

Table 5. Total area immunoreactive to the anti-oxidised LDL marker in the choroid and sclera calculated by means of colour morphometry $\left(\mu \mathrm{m}^{2}\right)$

(Mean values and standard deviations; median, minimum and maximum values)

\begin{tabular}{lccccccrr}
\hline Variable & Group & $n$ & Mean & Median & Minimum & Maximum & SD & $P^{*}$ \\
\hline Oxidised LDL-immunoreactive area & G1 & 11 & 5270 & 4862 & 3125 & 7571 & 1572 & \\
& G2 & 10 & 2009 & 2215 & 655 & 2984 & 777 & $<0.001$ \\
\hline
\end{tabular}

G1, cholesterol-enriched diet group; G2, cholesterol-enriched diet plus flaxseed supplementation group.

* Student $t$ test for independent samples $(P<0.05)$. 


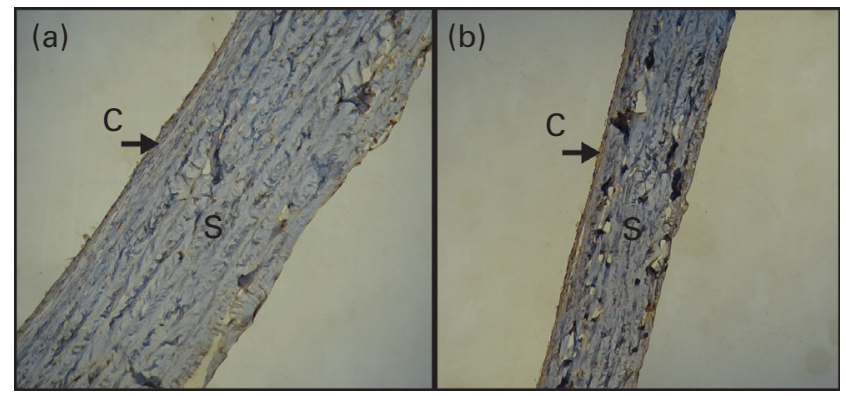

Fig. 2. Immunohistochemical analysis of choroid (C) and sclera (S) samples with the anti-oxidised LDL marker. Magnification 200x. (a) C-S complex of the cholesterol-enriched diet group. The $\mathrm{C}$ and $\mathrm{S}$ exhibited a high immunoreactivity to the anti-oxidised LDL marker, characterised by the predominance of a brownish hue. (b) $\mathrm{C}-\mathrm{S}$ complex of the cholesterolenriched diet plus flaxseed supplementation group. The $\mathrm{C}$ and $\mathrm{S}$ exhibited a low immunoreactivity to the anti-oxidised LDL marker, characterised by the predominance of a bluish hue.

in the choroid-sclera complex and, consequently, an increase in the thickness of the choroid and sclera as observed in the present study and in other studies ${ }^{(16,17,20,48)}$. From the ocular point of view, it is important to note that oxidised LDL, chemotactic molecules, adhesion molecules and macrophages are associated with the physiopathogenesis of AMD and may trigger or worsen this disease $\mathrm{e}^{(2,9,10,46-49)}$

As in the great vessels ${ }^{(26,27)}$, flaxseed flour supplemented to diet-induced hypercholesterolaemic rabbits (G2) reduced oxidised LDL expression in the choroid and sclera significantly. It is known that flaxseed is composed of PUFA, which, among other vascular effects, have anti-inflammatory properties and reduce leucocyte chemotaxis ${ }^{(21,22)}$. Similarly, flaxseed contains lignans, which inhibit the oxidation of PUFA, reducing LDL oxidation ${ }^{(26,50)}$. Hence, these factors may account for the significant reduction of oxidised LDL expression in the choroid-sclera complex of G2 rabbits when compared with G1 rabbits, contributing to a lower concentration of histiocytes in the choroid and sclera. It is important to point out that lignans also reduce the absorption of cholesterol in the intestine, reducing its serum concentrations ${ }^{(26,50,51)}$. This effect was observed in the present study; i.e. TC concentrations were significantly lower in G2 rabbits than in G1 rabbits, contributing directly or indirectly to the histomorphometric and immunohistochemical findings in the choroid-sclera complex of the animals treated with flaxseed flour.

The antioxidant action of flaxseed flour in the retina was evaluated using an anti-nitrotyrosine marker, considered to be a marker of NO and peroxynitrite ${ }^{(52)}$. NO exerts beneficial effects by promoting vasodilation and antiproliferation and may be considered antithrombotic. On the other hand, NO may exert damaging effects, such as cell lesion and apoptosis. Some of the damaging effects of $\mathrm{NO}$ are caused by the presence of peroxynitrite, a powerful oxidant that is formed by the reaction of $\mathrm{NO}$ and superoxide anion radical $\left(\mathrm{O}_{2}^{--}\right)^{(53)}$. Peroxynitrite mediates tyrosine nitration and nitrotyrosine formation, easily detected by anti-nitrotyrosine antibodies ${ }^{(52)}$ Conversely, cell apoptosis induced by an excessive increase in NO concentrations is caused by the constant elevation of intracellular $\mathrm{Ca}$ concentrations ${ }^{(54-56)}$. On the other hand, NOS, the enzyme responsible for the production of NO free radicals, has three established isoforms, NOS I, NOS II and NOS III, found in different parts of the eye ${ }^{(57,58)}$. As has been demonstrated earlier, hypercholesterolaemia induces an increase in $\mathrm{Ca}$ concentrations in the sensory retina ${ }^{(18)}$ and induces NOS-2 expression, increasing the oxidising injury of the retinal tissue ${ }^{(19)}$. It is known that NO is a major stimulator of choroidal neovascularisation in $\mathrm{AMD}^{(59)}$. In the present study, the retina of G1 rabbits (hypercholesterolaemic) exhibited a high immunoreactivity to the anti-nitrotyrosine marker, as documented in previous studies ${ }^{(19)}$. Flaxseed supplementation reduced nitrotyrosine expression significantly in G2 rabbits, and the decrease in serum cholesterol concentrations that it promoted may have contributed to this effect. On the other hand, we re-state that flaxseed also inhibits the oxidation of PUFA and reduces the oxidation of $\mathrm{LDL}^{(26,27)}$, factors that may have preserved the sensory retina of G2 animals.

In the present study, an immunohistochemical technique was used to analyse the sclera, choroid and retina of diet-induced hypercholesterolaemic rabbits. Immunohistochemistry, used to study paraffin-embedded material, enables the researcher to locate and identify the protein in the analysed tissue. We report that the Western blotting technique offers high-sensitivity detection and would improve the analysis of the studied protein. However, this technique is used to study fresh or frozen tissues. As the ocular globes were fixed in paraformaldehyde and then embedded in paraffin, it was not possible to complement the study with the Western blotting technique.

In the present study, it was possible to observe the beneficial effects of flaxseed on the biochemical variables such as TC and LDL-C concentrations, as well as on the choroid and sclera, of diet-induced hypercholesterolaemic rabbits. Nevertheless, future experiments should include an analysis of the plasma fatty acid composition and the plasma lignan content, so that the difference between the two groups

Table 6. Total area immunoreactive to the anti-nitrotyrosine marker in the retina calculated by means of colour morphometry $\left(\mu \mathrm{m}^{2}\right.$ ) (Mean values and standard deviations; median, minimum and maximum values)

\begin{tabular}{lcrrrrrrr}
\hline Variable & Group & $n$ & Mean & Median & Minimum & Maximum & SD & $P^{*}$ \\
\hline Nitrotyrosine-immunoreactive area & G1 & 11 & 12029 & 12505 & 5741 & 18856 & 3932 & \\
& G2 & 10 & 6867 & 5943 & 3155 & 11248 & 2555 & 0.002 \\
\hline
\end{tabular}

G1, cholesterol-enriched diet group; G2, cholesterol-enriched diet plus flaxseed supplementation group.

${ }^{\star}$ Student $t$ test for independent samples $(P<0.05)$. 


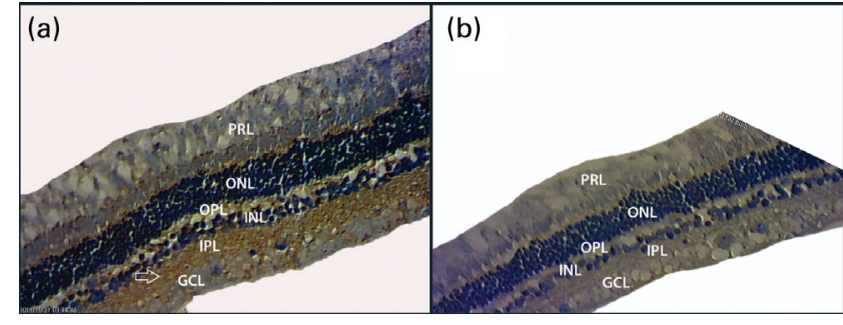

Fig. 3. Immunohistochemical analysis of retina samples with the antinitrotyrosine marker. (a) Retina of the cholesterol-enriched diet group. The retinal layers, mainly the inner plexiform layer, exhibited a high immunoreactivity to the anti-nitrotyrosine marker, characterised by the predominance of a brownish hue. (b) Retina of the cholesterol-enriched diet plus flaxseed supplementation group. The retinal layers exhibited a low immunoreactivity to the anti-nitrotyrosine marker, characterised by the predominance of a bluish hue. PRL, photoreceptor layer; ONL, outer nuclear layer; OPL, outer plexiform layer; INL, inner nuclear layer; IPL, inner plexiform layer; GCL, ganglion cell layer. Magnification 200x.

regarding the incorporation of the active component of flaxseed can be demonstrated.

Macrophages, oxidised LDL and reactive oxygen species, such as peroxynitrite, play an important role in the genesis of AMD. In the present study, flaxseed was found to preserve the choroid-sclera complex of rabbits fed a cholesterolenriched diet by inhibiting the migration of macrophages into the choroid and sclera. Flaxseed was also found to reduce LDL oxidation in the sclera, choroid and retina of these animals. Further studies are required to demonstrate whether, apart from the cardioprotective effect, flaxseed can also exert other beneficial effects in AMD

\section{Acknowledgements}

The authors are grateful to the staff of the Graduate Department of the Pontificia Universidade Catolica do Parana for their time and assistance and the Hospital Angelina Caron for allowing the use of the laboratories and equipment for the present experiment. They also thank Professor Marcia Olandoski for helping with the statistical analysis.

The present study received no specific grant from any funding agency or any commercial or not-for-profit sector.

The authors' contributions are as follows: R. J. d. A. T. made substantial contribution to the study conception and design, analysed and interpreted the data, drafted the manuscript, critically revised the manuscript, approved the final version of the manuscript to be submitted, and was responsible for administrative, technical and material support supervision; A. L. made substantial contribution to the study conception and design, drafted the manuscript, approved the final version of the manuscript to be submitted, and was in charge of the financial and management issues; A. S. B. made substantial contribution to the study conception and design, drafted the manuscript, approved the final version of the manuscript to be submitted, and was responsible for administrative, technical and material support supervision; L. B. P. and M. L. S. collected the data, critically revised the manuscript, approved the final version of the manuscript to be submitted, and carried out the statistical analysis; A. F. C. analysed and interpreted the data, drafted the manuscript, approved the final version of the manuscript to be submitted, and was responsible for technical and material support supervision; R. P. d. A. T. and N. F. d. F. S. collected the data, critically revised the manuscript, approved the final version of the manuscript to be submitted, and was responsible for administrative, technical and material support supervision; L. N. analysed and interpreted the data, critically revised the manuscript, approved the final version of the manuscript to be submitted, and was in charge of the financial and management issues; B. M. P. collected the data, critically revised the manuscript, approved the final version of the manuscript to be submitted, and was in charge of the financial and management issues; L. A. d. A. T. made substantial contribution to the study conception and design, critically revised the manuscript, approved the final version of the manuscript to be submitted, and was responsible for administrative, technical and material support supervision; D. B. P. analysed and interpreted the data, drafted the manuscript, approved the final version of the manuscript to be submitted, and was responsible for research group leadership.

None of the authors has any conflicts of interest to declare.

\section{References}

1. Friedman DS, O'Colmain BJ, Muñoz B, et al. (2004) Eye Diseases Prevalence Research Group. Prevalence of agerelated macular degeneration in the United States. Arch Ophthalmol 122, 564-572.

2. Ambati J, Ambati BK, Yoo SH, et al. (2003) Age-related macular degeneration: etiology, pathogenesis, and therapeutic strategies. Surv Ophthalmol 48, 257-293.

3. Pauleikhoff D, Harper CA, Marshall J, et al. (1990) Aging changes in Bruch's membrane: a histochemical and morphologic study. Ophthalmology 97, 171-178.

4. Ruberti JW, Curcio CA, Millican CL, et al. (2003) Quickfreeze/deep-etch visualization of age-related lipid accumulation in Bruch's membrane. Invest Ophthalmol Vis Sci 44, 1753-1759.

5. Ramrattan R, van der Schaft T, Mooy CM, et al. (1994) Morphometric analysis of Bruch's membrane, the choriocapillaris, and the choroid in aging. Invest Ophthalmol Vis Sci 35, 2857-2864.

6. Guidry C, Medeiros NE \& Curcio CA (2002) Phenotypic variation of retinal pigment epithelium in age-related macular degeneration. Invest Ophthalmol Vis Sci 43, 267-273.

7. Lutty G, Grunwald J, Majji AB, et al. (1999) Changes in choriocapillaris and retinal pigment epithelium in agerelated macular degeneration. Mol Vis 5, 35.

8. Korte GE, Reppucci V \& Henkind P (1994) RPE destruction causes choriocapillary atrophy. Invest Ophthalmol Vis Sci 25, 1135-1145

9. Sakurai E, Anand A, Ambati BK, et al. (2003) Macrophage depletion inhibits experimental choroidal neovascularization. Invest Ophthalmol Vis Sci 44, 3578-3585.

10. Grossniklaus HE, Ling JX, Wallace TM, et al. (2002) Macrophage and retinal pigment epithelium expression of angiogenic cytokines in choroidal neovascularization. Mol Vis 8, 119-126.

11. Tsutsumi C, Sonoda KH, Egashira K, et al. (2003) The critical role of ocular-infiltrating macrophages in the development of choroidal neovascularization. J Leukoc Biol 74, 25-32. 
12. Zhou J, Pham L, Zhang N, et al. (2005) Neutrophils promote experimental choroidal neovascularization. Mol Vis 11, 414-424.

13. Higgins GT, Wang JH, Dockery P, et al. (2003) Induction of angiogenic cytokine expression in cultured RPE by ingestion of oxidized photoreceptor outer segments. Invest Ophthalmol Vis Sci 44, 1775-1782.

14. Penfold PL, Provis JM \& Billson FA (1987) Age related macular degeneration: ultrastructural studies of the relationship of leucocytes to angiogenesis. Graefes Arch Clin Exp Ophthalmol 225, 70-76.

15. Torres RJ, Noronha Ld, Casella AM, et al. (2012) Increase of choroidal and scleral MCP-1 expression in hypercholesterolemia experimental model. Arq Bras Oftalmol 75, 48-52.

16. Torres RJ, Luchini A, Torres RRA, et al. (2014) Effect of candesartan on the expression of sclera-choroidal intercellular adhesion molecule-1 in hypercholesterolemic models. Clinics 69, 145-149.

17. Torres RJ, Muccioli C, Maia M, et al. (2010) Sclerochorioretinal abnormalities in hypercholesterolemic rabbits treated with rosiglitazone. Ophthalmic Surg Lasers Imaging $\mathbf{4 1}$, $562-571$.

18. Torres RJ, Maia M, Précoma DB, et al. (2009) Evaluation of early abnormalities of the sensory retina in a hypercholesterolemia experimental model: an immunohistochemical study. Arq Bras Oftalmol 72, 793-798.

19. Yücel I, Akar Y, Yücel G, et al. (2005) Effect of hypercholesterolemia on inducible nitric oxide synthase expression in a rat model of elevated intraocular pressure. Vision Res 45, 1107-1114.

20. Torres RJ, de Noronha L, Casella AM, et al. (2013) Increased VEGFR-1 immunoreactivity in the choroid-scleral complex in hypercholesterolemia experimental model. Arq Bras Oftalmol 76, 1-5.

21. Simopoulos AP (1999) Essential fatty acids in health and chronic disease. Clin Nutr 70, Suppl. 3, 560S-569S.

22. Uauy R \& Valenzuela A (2000) Marine oils: the health benefits of $n-3$ fatty acids. Nutrition 16, 680-684.

23. Seddon JM, Rosner B, Sperduto RD, et al. (2001) Dietary fat and risk for advanced age-related macular degeneration. Arch Ophthalmol 119, 1191-1199.

24. Chiu CJ, Hubbard LD, Armstrong J, et al. (2006) Dietary glycemic index and carbohydrate in relation to early agerelated macular degeneration. Am J Clin Nutr 83, 880-886.

25. SanGiovanni JP, Chew EY, Clemons TE, et al. (2007) The relationship of dietary lipid intake and age-related macular degeneration in a case-control study: AREDS report no. 20. Arch Ophthalmol 125, 671-679.

26. Prasad K (2009) Flaxseed and cardiovascular health. J Cardiovasc Pharmacol 54, 369-377.

27. Touré A \& Xueming X (2010) Flaxseed lignans: source, biosynthesis, metabolism, antioxidant activity, bio-active components, and health benefits. Compr Rev Food Sci Food Saf 9, 261-269.

28. Beatty S, Koh HH, Henson D, et al. (2000) The role of oxidative stress in the pathogenesis of age-related macular degeneration. Surv Ophthalmol 45, 115-314.

29. Camire ME \& Dougherty MP (2003) Raisin dietary fiber composition an in vitro bile acid binding. J Agric Food Chem $\mathbf{5 1}$, $834-837$.

30. Savaiano DA (2000) Cardiovascular disease and fiber: is insulin resistance the missing link? Nutr Rev 58, 356-358.

31. Dashti N, McGwin G, Owsley C, et al. (2006) Plasma apolipoproteins and risk for age related maculopathy. Br J Ophthalmol 90, 1028-1033.
32. Smeeth L, Cook C, Chakravarthy U, et al. (2005) A case control study of age related macular degeneration and use of statins. Br J Ophthalmol 89, 1171-1175.

33. Friedman $\mathrm{E}$ (2000) The role of the atherosclerotic process in the pathogenesis of age-related macular degeneration. $\mathrm{Am}$ $J$ Ophthalmol 130, 658-663.

34. Libby P (2002) Inflammation in atherosclerosis. Nature $\mathbf{4 2 0}$, 868-874.

35. Ross R (1999) Atherosclerosis: an inflammatory disease. $N$ Engl J Med 340, 115-126.

36. Nicolletti A, Caligiuri G \& Hansson GK (2000) Immunomodulation of atherosclerosis: myth and reality. J Intern Med 247, 397-405.

37. Kris-Entherton PM, Harris WS \& Appel LJ (2002) Fish consumption, fish oil, omega-3 fatty acids, and CVD. Circulation 106, 2747-2757.

38. Jenkis DJA, Kendall CWC, Marchie A, et al. (2002) Dose response of almonds on CHD risk factors: blood lipids, oxidized low-density lipoproteins, lipoprotein(a), homocysteine, and pulmonary nitric oxide: a randomized, controlled, crossover trial. Circulation 106, 1327-1332.

39. Cunnane SC, Ganguli S, Menard C, et al. (1993) High alphalinolenic acid flaxseed (Linum usitatissimum): some nutritional properties in humans. BrJ Nutr 69, 443-453.

40. Ratnayake WMN, Behrens W \& Fischer P (2007) Chemical and nutritional studies of flaxseed (variety Linott) in rats. $J$ Nutr Biochem 3, 232-240.

41. Shakir KAF \& Madhusudhan B (2007) Hypocholesterolemic and hepatoprotective effects of flaxseed chutney: evidence from animal studies. Indian J Clin Biochem 22, 117-121.

42. Prasad K (1999) Reduction of serum cholesterol and hypercholesterolemic atherosclerosis in rabbits by secoisolariciresinol diglucoside isolated from flaxseed. Circulation 99, 1355-1362.

43. Prasad K (2004) Hypocholesterolemic and antiatherosclerotic effect of flax lignan complex isolated from flaxseed. Atherosclerosis 179, 269-275.

44. Lucas EA, Lightfoot SA, Hammond LJ, et al. (2004) Flaxseed reduces plasma cholesterol and atherosclerotic lesion formation in ovariectomized Golden Syrian Hamsters. Atherosclerosis 173, 223-229.

45. Salazar JJ, Ramírez AI, de Hoz R, et al. (2007) Alterations in the choroid in hypercholesterolemic rabbits: reversibility after normalization of cholesterol levels. Exp Eye Res 84, 412-422.

46. Oh H, Takagi H, Takagi C, et al. (1999) The potential angiogenic role of macrophages in the formation of choroidal neovascular membranes. Invest Ophthalmol Vis Sci $\mathbf{4 0}$, 1891-1898.

47. Cousins SW, Espinosa-Heidmann DG \& Csaky KG (2004) Monocyte activation in patients with age-related macular degeneration. Arch Ophthalmol 122, 1013-1018.

48. Torres RJ, de Noronha L, Casella AM, et al. (2013) Effect of olmesartan on leukocyte recruitment in choroid-sclera complex in hypercholesterolemia model. J Ocul Pharmacol Ther 29, 709-714.

49. Sakurai E, Taguchi H, Anand A, et al. (2003) Targeted disruption of the CD18 or ICAM-1 gene inhibits choroidal neovascularization. Invest Ophthalmol Vis Sci 44, 2743-2749.

50. Westcott ND \& Muir AD (2003) Flax seed lignan in disease prevention and health promotion. Phytochem Ver 2, 401-417.

51. Prim CR, Baroncini LA, Précoma LB, et al. (2012) Effects of linseed consumption for a short period of time on lipid profile and atherosclerotic lesions in rabbits fed a hypercholesterolemic diet. BrJ Nutr 107, 660-664. 
52. Ischiropoulos H, Zhu L \& Beckman JS (1992) Peroxynitrite formation from macrophage derived nitric oxide. Arch Biochem Biophys 298, 446-451.

53. Lefer DJ, Scalia R, Campbell B, et al. (1997) Peroxynitrite inhibits leukocyte-endothelial cell interactions and protects against ischemia-reperfusion injury in rats. J Clin Invest 99, 684-691.

54. Suenobu N, Shichiri M, Iwashina M, et al. (1999) Natriuretic peptides and nitric oxide induce endothelial apoptosis via a cGMP-dependent mechanism. Arterioscler Thromb Vasc Biol 19, 140-146.

55. Hartmann BNA, Heller B, Jalowy A, et al. (1994) Nitric oxide toxicity in pancreatic islet cells: role of protein biosynthesis, calcium influx and arachidonic acid metabolism. Biochem Soc Trans 22, 23-26.
56. Boullerne AI, Nedelkoska L \& Benjamins JA (2001) Role of calcium in nitric oxide-induced cytotoxicity: EGTA protects mouse oligodendrocytes. J Neurosci Res 63, 124-135.

57. Behar-Cohen FF, Goureau O, D'Hermies F, et al. (1996) Decreased intraocular pressure induced by nitric oxide is correlated to nitrite production in the rabbit eye. Invest Ophthalmol Vis Sci 37, 1711-1715.

58. Park C-S, Pardhasaradhi K, Gianotti C, et al. (1994) Human retina expresses both constitutive and inducible isoforms of nitric oxide synthase mRNA. Biochem Biophys Res Commun 205, 85-91.

59. Ando A, Yang A \& Nambu H (2002) Blockade of nitric-oxide synthase reduces choroidal neovascularization. Mol Pharmacol 62, 539-544. 